\title{
Erythropoetin receptor expression in the human diabetic retina Shaival S Shah ${ }^{1,2}$, Stephen H Tsang ${ }^{2,3}$ and Vinit B Mahajan*1,2
}

Address: ${ }^{1}$ Vitreoretinal Service, Department of Ophthalmology and Visual Sciences, The University of Iowa Hospitals \& Clinics, 200 Hawkins Drive, USA, ${ }^{2}$ Omics Laboratory, Iowa City, IA, USA and ${ }^{3}$ Bernard and Shirlee Brown Glaucoma Laboratory, Department of Pathology and Cell Biology, Department of Ophthalmology, College of Physicians and Surgeons, Columbia University, New York, New York, USA

Email: Shaival S Shah - shaivalss@gmail.com; Stephen H Tsang - gene.targeting@gmail.com; Vinit B Mahajan* - mahajanlab@gmail.com

* Corresponding author

Published: 25 November 2009

BMC Research Notes 2009, 2:234 doi:10.1 186/1756-0500-2-234
Received: 9 November 2009

Accepted: 25 November 2009

This article is available from: http://www.biomedcentral.com//756-0500/2/234

(c) 2009 Mahajan et al; licensee BioMed Central Ltd.

This is an Open Access article distributed under the terms of the Creative Commons Attribution License (http://creativecommons.org/licenses/by/2.0), which permits unrestricted use, distribution, and reproduction in any medium, provided the original work is properly cited.

\begin{abstract}
Background: Recent evidence suggests erythropoietin (EPO) and the erythropoietin receptor $(E P O R)$ may play a direct role in the pathogenesis of diabetic retinopathy. Better characterization of the EPO-EPOR signaling system in the ischemic retina may offer a new therapeutic modality for ischemic ophthalmic diseases. This study was performed to identify EPOR mRNA expression in the human diabetic eye.

Findings: EPOR antisense RNA probes were validated on human pancreas tissue. In the normal eye, EPOR was expressed in the retinal ganglion cell layer. Minimal expression was observed in the inner and outer nuclear layer. Under conditions of diabetic retinopathy, EPOR expression shifted to photoreceptor cells. Increased expression was also observed in the peripheral retina.
\end{abstract}

Conclusion: EPOR expression may be a biomarker or contribute to disease mechanisms in diabetic retinopathy.

\section{Background}

Human erythropoietin (EPO) is the primary regulator of erythropoiesis, stimulating growth and promoting differentiation of red blood cell progenitors[1]. The primary stimulus for EPO release is decreased oxygen delivery, most often due to anemia or hypoxia[2]. EPO is an acidic glycoprotein hormone that is produced by the kidney and to a much lesser degree ( $<10$ percent) the liver. EPO binds to transmembrane epogen receptors (EPOR), which are expressed primarily by hematopoietic progenitor cells but also by nonhematopoietic cells and tissues such as endothelial cells, cardiomyocytes, and neurons, the liver, uterus, and retina[3]. EPO also shows angiogenic activity in vitro by stimulating vascular endothelial cells to proliferate and migrate[4]. EPO is now also known as a potent antiapoptotic factor for EPOR presenting cells, particularly neural cells[5].

EPO may play a direct role in the pathophysiology of diabetic retinopathy. Vitreous levels of EPO are higher in diabetic patients, suggesting that EPO may be produced as an endogenous neuroprotectant against ischemia. Compared with the proangiogenic vascular endothelial growth factor, EPO is more strongly associated with proliferative diabetic retinopathy than VEGF[6]. In diabetic rats, intravitreal injection of EPO upregulated EPOR in the neurosensory retina and had a protective effect on vascular and photoreceptor cells[7]. In a mouse model of oxygen-induced retinopathy inhibition of EPO by injection of intravitreal EPO siRNA suppressed retinal neovascular- 
ization[8]. Inhibition of systemic EPO production has been clinically observed in early diabetic nephropathy and results in anemia that is associated with an aggravated course of DR[9]. Intravenous administration of EPO to treat azotemia-induced anemia in diabetic patients demonstrated a beneficial effect on macular edema and improved visual outcome[10]. In a cross-sectional study of 1691 diabetic patients, the severity of anemia correlated with the severity of PDR[11]. Friedman reported 5 cases in which patients with severe anemia and PDR had substantial reduction of macular hard exudates after treatment with systemic EPO[12].

Identifying the target cells and conditions regulating EPOR expression is important when considering therapeutic intervention. In a study of post-mortem retinas of 9 patients with diabetes but without diabetic retinopathy, EPOR was detected in the neuroretina and in the retinal pigment epithelium. No difference in expression of EPOR between diabetic eyes and non-diabetic was observed eyes[13]. However, they did not report which layers of the neuroretina they detected expression.

Evidence for EPOR localization in mice has been contradictory. Chen et. al showed EPOR to be expressed in all layers of the inner retina and predominantly in the ganglion cell layer[14]. Kilic and associates also showed localization to the ganglion cell layer[15]. However, Grimm and associates have evidence of its localization to photoreceptors[16]. Hypoxia is a potent trigger for EPO and EPOR expression, and a growing body of evidence suggests hypoxia may induce changes in the expression of EPOR in the eye. Compared with age-matched controls, EPO mRNA expression levels are greatly increased in the retinas of mice under hypoxic conditions[14].

While antibodies suitable for EPOR detection in mouse tissues exist, they lack specificity for human EpoR[17]. For this reason mRNA in situ hybridization experiments were performed to identify cellular EPOR expression in the human diabetic retinopathy eye.

\section{Results}

Gross examination of the diabetic eye showed extensive photocoagulation scars throughout the peripheral retina. The vitreous was collapsed and there was a membrane overlying the posterior pole. The macula appeared edematous. (Figure 1A) These findings were consistent with prior treatment of proliferative diabetic retinopathy where the surviving retinal cells would have been subjected to severe ischemia, especially in the peripheral retina. A representative fluorescein angiogram of retinopathy from diabetes is shown. In such cases, there is extensive capillary loss, which is more pronounced in the retinal periphery[18]. (Figure 1B) The eye was sectioned and histological examination of the posterior retina showed preretinal fibrosis, nerve fiber layer edema, variable cell loss especially in the photoreceptor layer, tractional retinal detachment, and retinal pigment epithelial hyperplasia. (Figure 1C) The retina became thinner in the periphery and there was cell loss and abnormal tissue and cytoarchitecture. (Figure 1D)

To better understand EPOR expression in the ischemic retina, an in situ hybridization assay was developed. To validate the assay, EPOR antisense probes were first applied to human pancreatic sections where EPOR is highly expressed. Expression was seen in the acinar cells and vessel lumen endothelial cells as previously described [4,19] (Figure 2). Only a minimal, non-specific signal was observed with the sense probe (Figure 2) or unlabeled probe (data not shown).

The posterior retina was then examined. In the normal human eye, EPOR was expressed in the retinal ganglion cell layer. No expression was observed in the inner or outer nuclear or plexiform layers. (Figures 3A - C) In contrast, the diabetic retina showed increased expression in the photoreceptor cells in addition to expression in the retinal ganglion cell layer. (Figures 3D - F)

In the retinal periphery, the retinal thickness and number of cells normally decreases. In the normal eye there was a corresponding decrease in EPOR signal. (Figures 4A - C) In the diabetic retina, however, there was a significantly higher increase in EPOR signal. This did not correspond to increased numbers of cells or thicker tissue. Rather, there was loss of cells and disruption of the normal tissue and cytoarchitecture, and it was not possible to assign this expression to a specific cell type or layer (Figures 4D-F). Comparison to control sense probe sections suggested the hybridization signal was not due to increased background.

\section{Discussion}

Reports of expression of EPOR in the human diabetic retina in diabetics is limited without indication of cellular origin. One report detected EPOR in human epiretinal membrane of proliferative diabetic retinopathy[20]. EPOR was detected in retinal and RPE extracts of patients with diabetes, but these patients had no evidence of ischemia or retinopathy[13].

Our results reveal EPOR mRNA is expressed primarily in the ganglion cell layer of the human retina under normal conditions $[14,15]$. Although absent from in human photoreceptors under normal conditions, our results suggest that EPOR is upregulated in photoreceptors during diabetic retinopathy. The high metabolic rate of darkadapted photoreceptors can lead to borderline hypoxic 

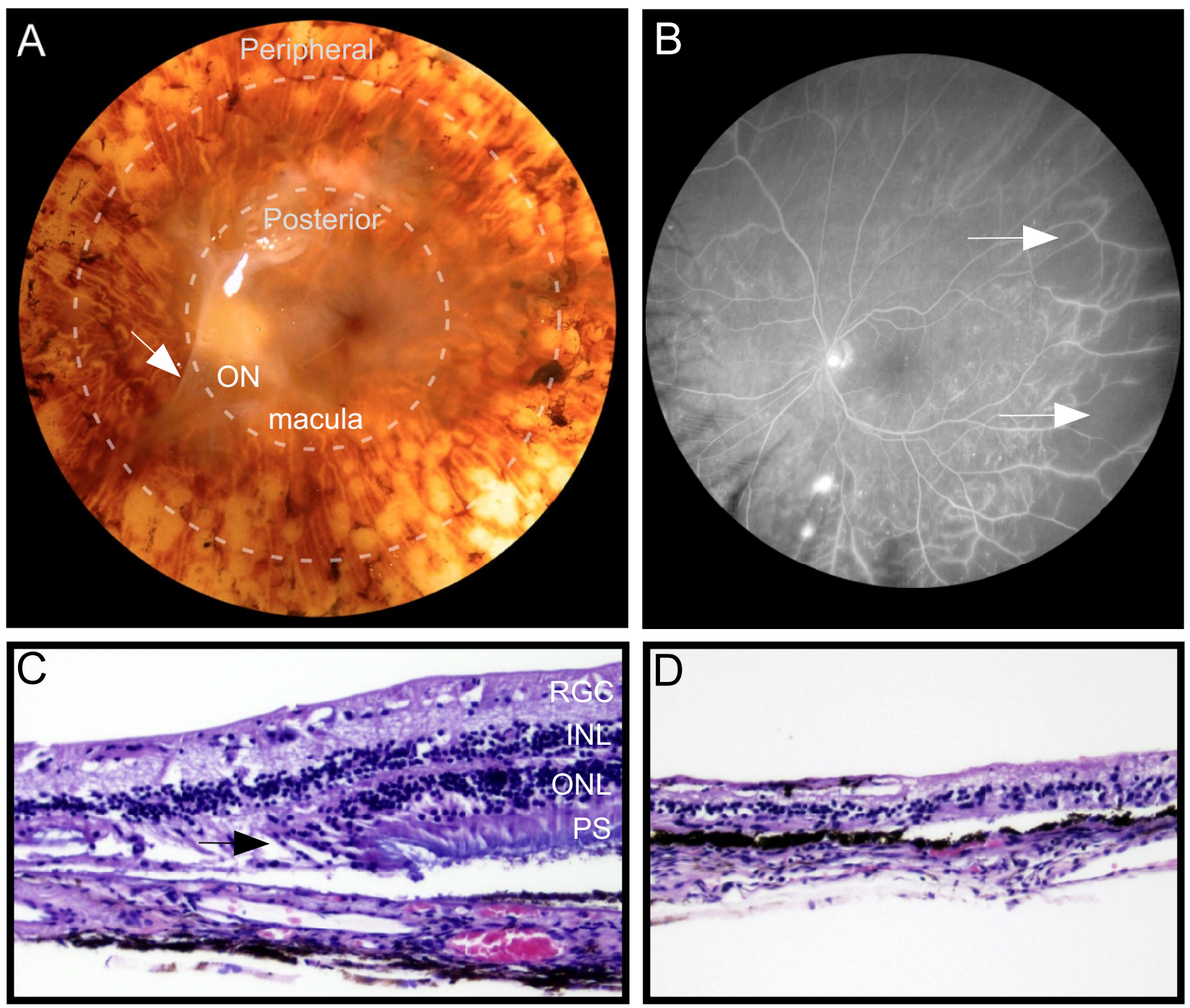

Figure I

Regressed Proliferative Diabetic Retinopathy. A, Gross view of eye. There was a membrane (arrow) overlying the macula and optic nerve head (ON). Peripheral to this were laser photocoagulation scars. Dotted lines show the posterior and peripheral retina. B, Representative fluorescein angiogram showing capillary dropout (arrows) and peripheral ischemia. C, H\&E section of the posterior retina shows variable cell and photoreceptor segment loss (arrow). D, H\&E section of the peripheral retina shows extreme cell loss and disorganized cytoarchitecture. Abbreviations: H\&E, heamotoxylin and eosin; ON, optic nerve; RGC, retinal ganglion cell layer; INL, inner nuclear layer; ONL outer nuclear layer; RPE, retinal pigment epithelium layer; PS, photoreceptor segments.

levels in the normal retina, so photoreceptors may be particularly susceptible to hypoxia[21]. Our finding of increased EPOR expression in the peripheral retina most likely indicates increased hypoxia/ischemia in these areas. This is consistent with current understanding of the pathogenesis of diabetic retinopathy, in which retinal capillary non-perfusion results in retinal ischemia initially in the mid-retinal periphery[22]. The distortion of the cytoarchitecture of the human diabetic retina in our study is likely a consequence of extensive panretinal photocoagulation treatment. Increased EPOR expression may reflect increased hypoxia, and may be an endogenous attempt by the body to protect the retina from hypoxia with the neuroprotective properties of EPO.

Hypoxia is a potent stimulus of increased EPO production. Retinal EPO mRNA levels were increased in mice in a dose-dependent manner following hypoxia[16]. It is 

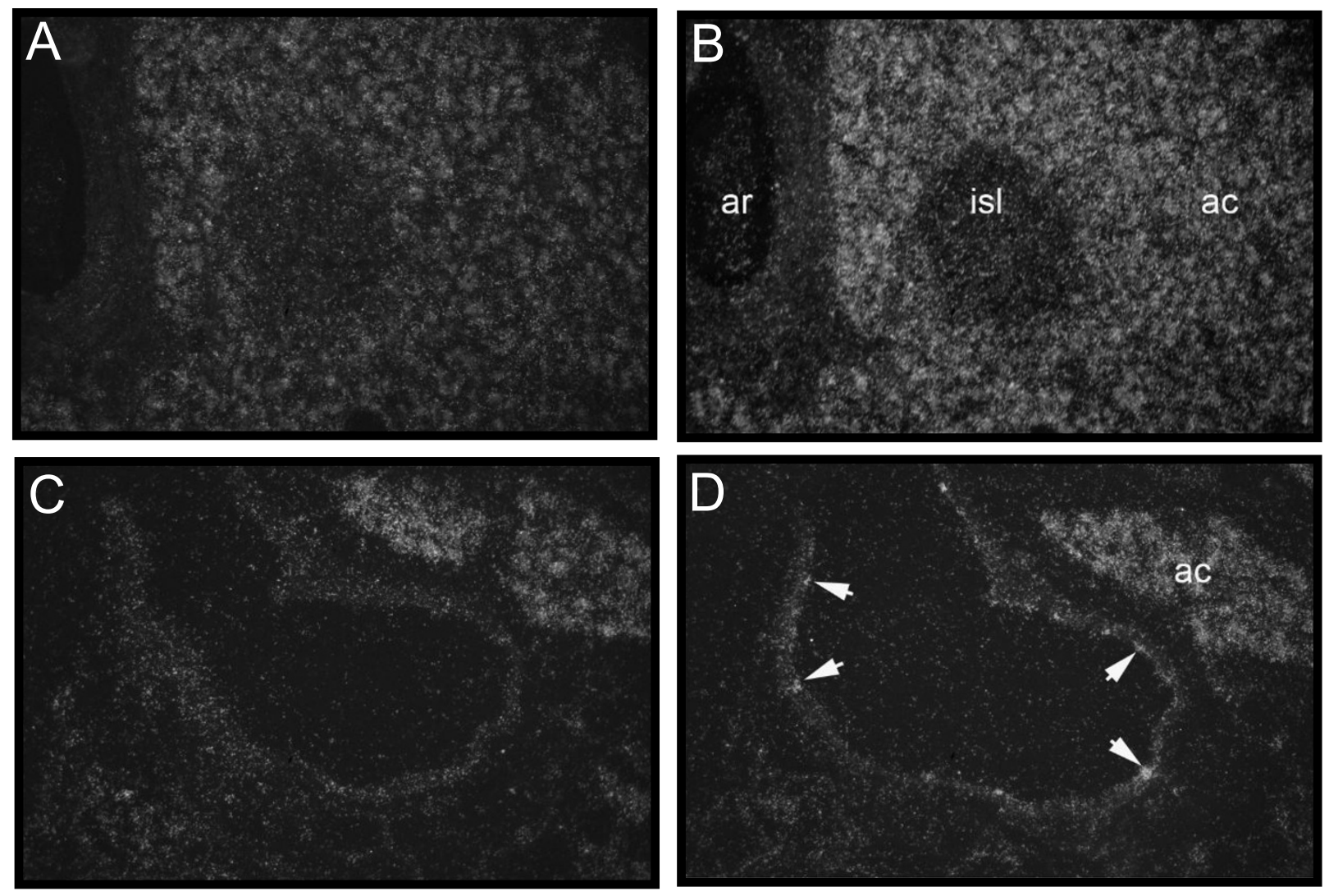

\section{Figure 2}

EpoR probe validation in human pancreatic tissue. A, A section of human pancreatic tissue with sense RNA probes for EpoR. B, Same tissue with anti-sense RNA probes for EpoR, demonstrating increased expression in islet of Langerhans cells. C, A section of human pancreatic tissue showing a vein adjacent to an acinar cell, with sense RNA probes. D, The same tissue with anti-sense RNA probes for EpoR, demonstrating expression in the endothelium of the vein (arrows). Abbreviations: ac, acinar cells; ar, artery; isl, islet of Langerhans.

thought that EPO may function as an endogenous neuroprotectant. In a mouse-model of retinal detachment, in which photoreceptors die from ischemia, Xie and colleagues demonstrated that there is upregulation of the EPO-EPOR system[23]. Other studies demonstrated in a mouse-model that levels of both EPO mRNA and EPOR mRNA increased in the retinas of mice during hypoxiainduced retinal neovascularization[8]. The angiogenic properties might be relevant in the peripheral retina, which is the site of neovascularization in proliferative diabetic retinopathy. Increased expression is found in other organ systems, including the spleen and brain, where the EPO/EPOR signaling system is upregulated under conditions of hypoxia[24,25].
The EPO/EPOR signaling system may contribute to the survival of neurons through a variety of mechanisms including inhibition of apoptosis, a reduction in reactive oxidative species, a reduction in proinflammatory cytokines, recruitment of stem cells and maintenance of vascular autoregulation lending protection from ischemic damage[26]. Transcriptional regulation of EPO expression by hypoxia-inducible factor-1 (HIF1 $\alpha$ ) maintains survival of cone photoreceptors against genetic insults[27]. EPO promotes neural outgrowth from retinal ganglion cells in a dose-dependent manner and preserves their survival after axotomy[28]. Additionally, hypoxiainduced retinal EPO expression appears to protect retinal neurons from transient global ischemic and reperfusion 

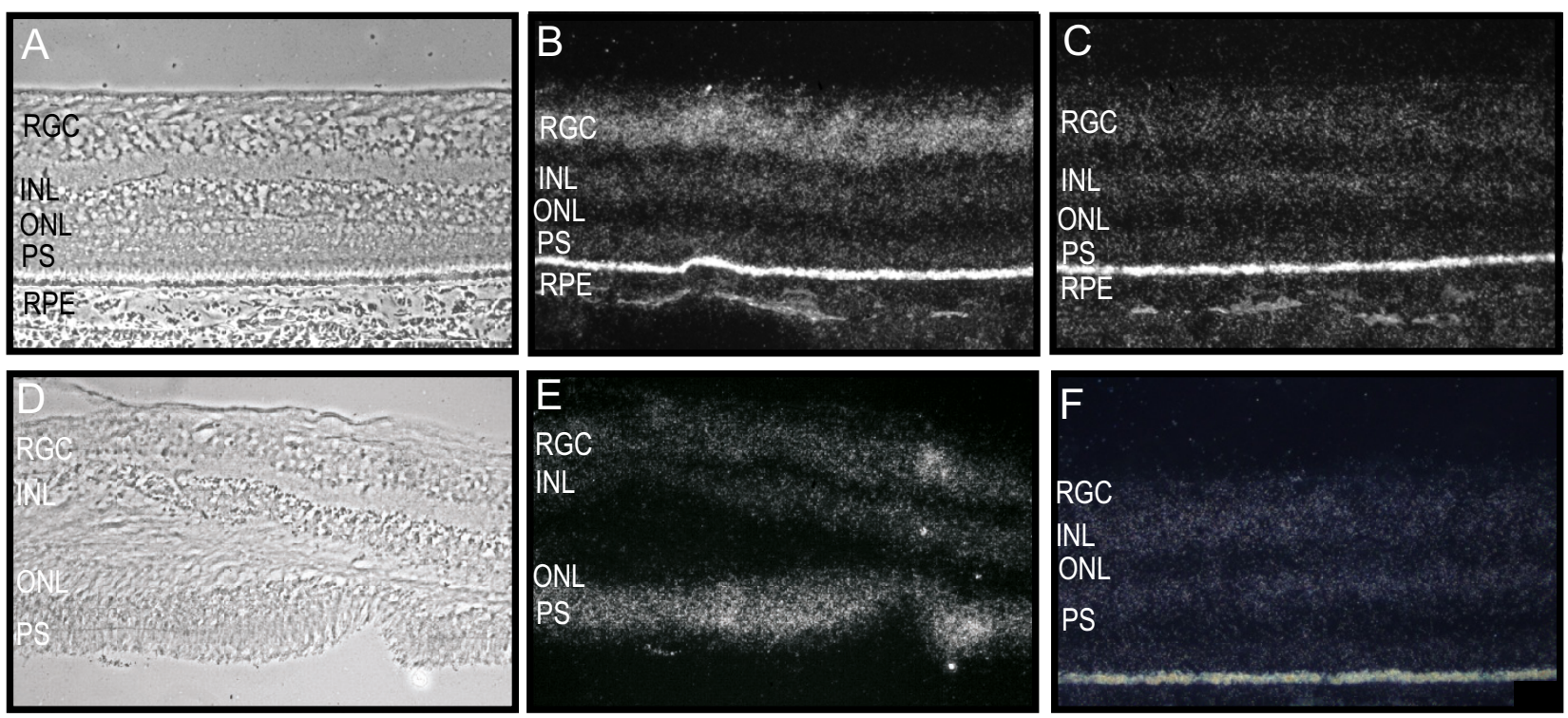

\section{Figure 3}

EpoR mRNA expression in the posterior normal (A-C) and diabetic (D-F) retina. A, Phase contrast micrograph of a normal human retina. B, Anti-sense RNA probes for EpoR in normal retina. C, Control sense RNA probes for EpoR in normal retina demonstrates expression in the retinal ganglion cell layer. $\mathbf{D}$, Phase contrast micrograph of a diabetic human retina with an artifactual detachment. E, Anti-sense sense RNA probes for EpoR in diabetic retina. F, Control sense RNA probes for EpoR shows decreased expression in the RGC layer and an increase in the photoreceptor segments. Abbreviations: RGC, retinal ganglion cell layer; INL, inner nuclear layer; ONL outer nuclear layer; RPE, retinal pigment epithelium layer; PS, photoreceptor segments.

injury through an anti-apoptotic pathway[29]. There is evidence that systemic EPO administration may protect retinal photoreceptors from light-induced apoptotic pathways in retinal degeneration models.

Pathologic angiogenesis is a final common pathway in ischemic ocular diseases. In proliferative diabetic retinopathy, catastrophic vision loss is often the result of neovascular membranes that lead to hemorrhage, fibrosis, and retinal detachment[30]. The destruction of retinal tissue with laser photocoagulation is thought to mitigate retinal ischemia, and remains the established treatment for diabetic retinal neovascularization[30]. The molecular mechanisms underlying the ischemic drive for proliferative diabetic retinopathy are poorly understood, and development of more effective and less destructive therapy is necessary.

\section{Conclusion}

Our findings suggest in the human retina, EPOR mRNA is primarily expressed in the ganglion cell layer. Under conditions of ischemia such as diabetic retinopathy, there may be up-regulation of EPOR expression in the photoreceptors and in the peripheral retina.
Future studies with additional samples may lead to more conclusive answers regarding the potential role of EPO in diabetic retinopathy. Nevertheless, our results support the concept that a dynamic EPO-EPOR signaling system is present in the ischemic retina and may offer a new therapeutic modality for ischemic ophthalmic diseases. Given its neurotrophic properties, EPO may be an ideal candidate to signal retinal ganglion cells or photoreceptors in anterior ischemic optic neuropathy or central retinal artery occlusion where there are currently no effective treatments. Careful inhibition of EPO may prove to be an effective way to treat or prevent diabetic retinopathy and other forms of angiogenesis. Ultimately, clinical application and regulation of the EPO/EPOR system will require careful dosing so that vessel proliferation is inhibited without impairment of neuronal survival.

\section{Methods}

This study adhered to the tenets of the Declaration of Helsinki and was approved by the Institutional Review Board. Post-mortem retinas from two eyes were obtained from a 68 year-old male with regressed proliferative diabetic retinopathy and end-stage renal disease and peripheral vascular disease. This was compared to two retinas form 

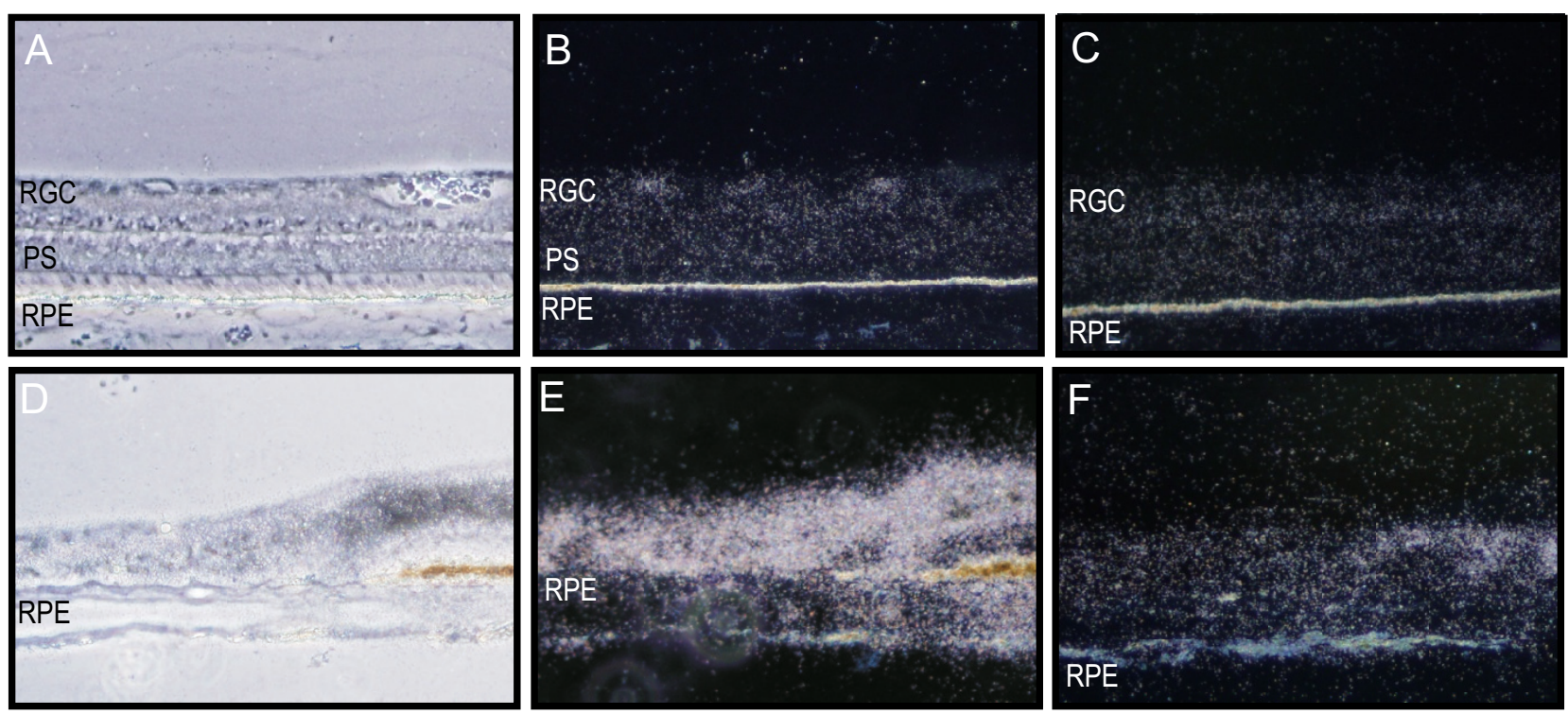

Figure 4

EpoR mRNA expression in the peripheral normal (A-C) and diabetic (D-F) retina. A, Phase contrast micrograph of the peripheral normal human retina. B, Anti-sense RNA probes for EpoR in normal retina demonstrates expression in the few retinal ganglion cells present in the peripheral retina. C, Control sense RNA probes for EpoR in normal retina. D, Phase contrast micrograph of a diabetic human retina shows loss of cytoarchitecture. E, Anti-sense RNA probes for EpoR shows intense signal in the peripheral retina. F, Control sense RNA probes for EpoR in diabetic retina. Abbreviations: RGC, retinal ganglion cell layer; INL, inner nuclear layer; ONL outer nuclear layer; RPE, retinal pigment epithelium layer; PS, photoreceptor segments.

an age and sex-matched donor eyes without diabetes or other ophthalmic pathology. Human retina and archived human pancreatic sections were fixed overnight, dehydrated and infiltrated with paraffin. Serial 5 to $8 \mu \mathrm{m} \mathrm{sec}-$ tions were mounted on gelatin-coated slides, deparaffinized in xylene and rehydrated in a series of ethanols and PBS. The sections were digested with proteinase $\mathrm{K}$, treated with triethanolamine/acetic anhydride, washed and dehydrated.

The cRNA transcripts were synthesized in vitro according to manufacturer's conditions (Ambion) and labeled with ${ }^{35}$ S-UTP (> $1000 \mathrm{Ci} / \mathrm{mmol}$; Amersham). Sections were hybridized overnight at $55^{\circ} \mathrm{C}$ in $50 \%$ deionized formamide, $0.3 \mathrm{M} \mathrm{NaCl}, 20 \mathrm{mM}$ Tris- $\mathrm{HCl} \mathrm{pH}$ 7.4, 5 mM EDTA, $10 \mathrm{nM}$ NaPO4, 10\% dextran sulphate, $1 \times$ Denhardt's, 50 $\mu \mathrm{g} / \mathrm{ml}$ total yeast RNA, and $50-80,000 \mathrm{cpm} / \mu \mathrm{l}{ }^{35} \mathrm{~S}$-labeled cRNA probe. The tissue was subjected to stringent washing at $65^{\circ} \mathrm{C}$ in $50 \%$ formamide, $2 \times$ SSC, $10 \mathrm{mM}$ DTT and washed in PBS before treatment with $20 \mu \mathrm{g} / \mathrm{ml}$ RNAse A at $37^{\circ} \mathrm{C}$ for 30 minutes. Following washes in $2 \times$ SSC and $0.1 \times$ SSC for 10 minutes at $37^{\circ} \mathrm{C}$, slides were dehydrated, exposed to $\mathrm{x}$-ray film for 5 days, then dipped in Kodak NTB nuclear track emulsion and exposed for 18 days in light-tight boxes with desiccant at $4{ }^{\circ} \mathrm{C}$. Photographic development was carried out in Kodak D-19. Slides were counterstained lightly with hematoxylin and eosin and analyzed using both bright- and darkfield optics. Sense control cRNA probes (identical to the mRNAs) always gave background levels of hybridization signal.

\section{Competing interests}

The authors declare that they have no competing interests.

\section{Authors' contributions}

SST and VBM designed and conducted the experiments and conceived the initial idea. All authors contributed equally in analyzing and interpreting the data. SSS and VBM drafted the manuscript. All authors read and approved the final manuscript.

\section{Acknowledgements}

We thank the efforts of Patricia Duffel, M.A., for her assistance in preparation of this manuscript. Supported by unrestricted funds from Research to Prevent Blindness, New York, NY, ROIEYOI82I3 (SHT), the Foundation Fighting Blindness, Schneeweiss Stargardt Fund, and The Starr Foundation. SHT is a Fellow of the Burroughs-Wellcome Program in Biomedical Sciences, and has been salaried by the Bernard Becker-Association of University Professors in Ophthalmology-Research to Prevent Blindness Award, 
Dennis W. Jahnigen Award of the American Geriatrics Society, Joel Hoffman Trust, Gale and Richard Siegel Stem Cell Fund, Charles Culpeper Scholarship Fund, Schneeweiss Stem Cell Fund, Crowley Family Research Fund, Bernard and Anne Spitzer Stem Cell Fund, Barbara \& Donald Jonas Family Fund, and Eye Surgery Fund.

\section{References}

I. Krantz SB: Erythropoietin. Blood 1991, 77:419-434

2. Erslev AJ: Erythropoietin. N Engl] Med I99I, 324:1339-I344.

3. Farrell F, Lee $A$ : The erythropoietin receptor and its expression in tumor cells and other tissues. Oncologist 2004, 9:18-30.

4. Anagnostou A, Liu Z, Steiner M, Chin K, Lee ES, Kessimian N, Noguchi CT: Erythropoietin receptor mRNA expression in human endothelial cells. Proc Natl Acad Sci USA 1994, 91:3974-3978.

5. Walshe TE, D'Amore PA: The role of hypoxia in vascular injury and repair. Annu Rev Pathol 2008, 3:6I5-643.

6. Watanabe D, Suzuma K, Matsui S, Kurimoto M, Kiryu J, Kita M, Suzuma I, Ohashi H, Ojima T, Murakami T, et al.: Erythropoietin as a retinal angiogenic factor in proliferative diabetic retinopathy. N Engl J Med 2005, 353:782-792.

7. Zhang J, Wu Y, Jin Y, Ji F, Sinclair SH, Luo Y, Xu G, Lu L, Dai W, Yanoff $M$, et al.: Intravitreal injection of erythropoietin protects both retinal vascular and neuronal cells in early diabetes. Invest Ophthalmol Vis Sci 2008, 49:732-742.

8. Chen J, Connor KM, Aderman CM, Willett KL, Aspegren OP, Smith LE: Suppression of retinal neovascularization by erythropoietin siRNA in a mouse model of proliferative retinopathy. Invest Ophthalmol Vis Sci 2009, 50:1329-1335.

9. Cotroneo P, Maria Ricerca B, Todaro L, Pitocco D, Manto A, Ruotolo V, Storti S, Damiani P, Caputo S, Ghirlanda G: Blunted erythropoietin response to anemia in patients with Type I diabetes. Diabetes Metab Res Rev 2000, 16:172-176.

10. Friedman EA, L'Esperance FA, Brown CD, Berman DH: Treating azotemia-induced anemia with erythropoietin improves diabetic eye disease. Kidney Int Suppl 2003, 64:S57-63.

II. Qiao Q, Keinanen-Kiukaanniemi S, Laara E: The relationship between hemoglobin levels and diabetic retinopathy. J Clin Epidemiol 1997, 50:153-I58.

12. Friedman EA, Brown CD, Berman DH: Erythropoietin in diabetic macular edema and renal insufficiency. Am J Kidney Dis 1995, 26:202-208.

13. Garcia-Ramirez M, Hernandez C, Simo R: Expression of erythropoietin and its receptor in the human retina: a comparative study of diabetic and nondiabetic subjects. Diabetes Care 2008, 3 I: I 189-I I94.

14. Chen J, Connor KM, Aderman CM, Smith LE: Erythropoietin deficiency decreases vascular stability in mice. J Clin Invest 2008, I | 8:526-533.

15. Kilic U, Kilic E, Soliz J, Bassetti Cl, Gassmann M, Hermann DM Erythropoietin protects from axotomy-induced degeneration of retinal ganglion cells by activating ERK-I/-2. FASEB J 2005, I 9:249-25I.

16. Grimm C, Wenzel A, Groszer M, Mayser H, Seeliger M, Samardzija M, Bauer C, Gassmann M, Reme CE: HIF-I-induced erythropoietin in the hypoxic retina protects against light-induced retinal degeneration. Nat Med 2002, 8:718-724.

17. Elliott S, Busse L, Bass MB, Lu H, Sarosi I, Sinclair AM, Spahr C, Um $M$, Van G, Begley CG: Anti-Epo receptor antibodies do not predict Epo receptor expression. Blood 2006, I 07: 1892-1895.

18. Speiser P, Gittelsohn AM, Patz A: Studies on diabetic retinopathy. 3. Influence of diabetes on intramural pericytes. Arch Ophthalmol 1968, 80:332-337.

19. Fenjues ES, Ochoa MS, Cabrera O, Mendez AJ, Kenyon NS, Inverardi $L$, Ricordi C: Human, nonhuman primate, and rat pancreatic islets express erythropoietin receptors. Transplantation 2003, 75: $1356-1360$

20. Kase S, Saito W, Ohgami K, Yoshida K, Furudate N, Saito A, Yokoi M, Kase M, Ohno S: Expression of erythropoietin receptor in human epiretinal membrane of proliferative diabetic retinopathy. Br J Ophthalmol 2007, 91:1376-1378.

21. Steinberg RH: Monitoring communications between photoreceptors and pigment epithelial cells: effects of "mild" systemic hypoxia. Friedenwald lecture. Invest Ophthalmol Vis Sci 1987, 28:1888-1904.
22. Cai J, Boulton M: The pathogenesis of diabetic retinopathy: old concepts and new questions. Eye (London, England) 2002, I 6:242-260.

23. Xie Z, Wu X, Qiu Q, Gong Y, Song Y, Gu Q, Li C: Expression pattern of erythropoietin and erythropoietin receptor in experimental model of retinal detachment. Curr Eye Res 2007 32:757-764.

24. Spandou E, Papoutsopoulou S, Soubasi V, Karkavelas G, Simeonidou C, Kremenopoulos G, Guiba-Tziampiri O: Hypoxia-ischemia affects erythropoietin and erythropoietin receptor expression pattern in the neonatal rat brain. Brain Res 2004, I02I:|67-|72.

25. Tan CC, Eckardt KU, Firth JD, Ratcliffe PJ: Feedback modulation of renal and hepatic erythropoietin mRNA in response to graded anemia and hypoxia. Am J Physiol Renal Physiol 1992, 263:F474-48I.

26. Matsuda N, Hayashi H, Miyatake S, Kuroiwa T, Kagamiyama H: Instability of the apo form of aromatic L-amino acid decarboxylase in vivo and in vitro: implications for the involvement of the flexible loop that covers the active site. J Biochem 2004, 1 35:33-42.

27. Punzo C, Cepko C: Cellular responses to photoreceptor death in the rdI mouse model of retinal degeneration. Invest Ophthalmol Vis Sci 2007, 48:849-857.

28. Böcker-Meffert S, Rosenstiel P, Rohl C, Warneke N, Held-Feindt J, Sievers J, Lucius R: Erythropoietin and VEGF promote neural outgrowth from retinal explants in postnatal rats. Invest Ophthalmol Vis Sci 2002, 43:2021-2026.

29. Junk AK, Mammis A, Savitz SI, Singh M, Roth S, Malhotra S, Rosenbaum PS, Cerami A, Brines M, Rosenbaum DM: Erythropoietin administration protects retinal neurons from acute ischemia-reperfusion injury. Proc Natl Acad Sci USA 2002, 99: 10659-10664.

30. Mohamed Q, Gillies MC, Wong TY: Management of diabetic retinopathy: a systematic review. JAMA 2007, 298:902-916.
Publish with Biomed Central and every scientist can read your work free of charge

"BioMed Central will be the most significant development for disseminating the results of biomedical research in our lifetime. "

Sir Paul Nurse, Cancer Research UK

Your research papers will be:

- available free of charge to the entire biomedical community

- peer reviewed and published immediately upon acceptance

- cited in PubMed and archived on PubMed Central

- yours - you keep the copyright
BioMedcentral 